\title{
CORRESPONDENCE.
}

\section{On the Treatment of a Certain Class of Destructive Patients.}

I.

Middlesex County Lunatic Asylum, Colney Hatch, N., December 10th, 1869.

Sir,-In some correspondence which has lately passed between the Committee of Visitors of this Asylum and the Commissioners in Lunacy on the subject of providing bedsteads and bedding for patients of a wilfully destructive nature, the Commissioners have expressed themselves as strongly of opinion that the practice, occasionally resorted to at this asylum, of taking away, for a limited period of time, the usual bedsteads and bedding from such patients who persistently destroy them, and putting them in single rooms with an ample supply of strong quilted rugs, is " unjustifiable in any case."

As a guide to them in their future action in these cases, the Committee would feel much obliged by your informing them what is the course pursued at the Asylum under your charge ; and they desire me to ask you to favour them with a description of the mode of treatment you adopt in the cases of patients who without being under the effects of any sudden paroxysm, are so violent and destructive as persistently to break up the bedsteads and tear in pieces the bedding with which they are supplied. The Committeee specially desire information whether in the event of patients destroying their bedding in the early part of the night, the same is renewed to them as often as they destroy that which had been previously supplied, or whether they are left without any bedding for the remainder of the night on which they have exhibited thir destructive tendencies.

To prevent any misapprehension as to the practice adopted at the Colney Hatch Asylum, I beg to inform you that when the ordinary bedding is taken away from the patients, they are, in lieu thereof, supplied with three warm quilted rugs which, if used, afford them ample protection against the cold, and and of which, after attempting in vain to destroy them, they usually avail themselves as a covering.

The favour of an early reply will oblige the Committee.

$$
\text { I am, Sir, }
$$

Your obedient Servant,

JoHN S. SKaIFE,

Clerk to the Visitors.

To the Superintendent of the Sussex Asylum.

II.

Sussex Lunatic Asylum,

Hayward's Heath, December, 15, 1869.

SIR, - I had the honour to receive this morning your letter, dated December, 10th, making enquiries relative to the treatment of a certain class of destructive patients in this Asylum.

I. I most strongly, after an experience here of ten years, endorse the opinion of the Commistioners in Lunacy to which you refer, that it is unjustifiable in any 
case to place patients of destructive habits, even for a limited period in seclusion, without clothing or bedding, although an ample supply of strong quilted rugs be, as you say, given. A patient placed as you describe, reminds me of Hogarth's picture of Old Bedlam in "The Rake s Progress." The authorities then allowed straw instead of strong quilted rugs.

This question which you now re-open, was brought before the profession by the Medical Superintendent of the male department of Colney Hatch, in a paper which he published in the "Journal of Mental Science" for April, 1867, "On the treatment of a certain class of Destructive Patients." His views were, to my judgment, refuted in a paper by my colleague, Dr. S. W. D. Williams, in the July number of the same Journal, "The non-restraint system in the treatment of a certain class of Destructive Patients."

Dr. Sheppard replied to this in the October number, "Some further Observations in reply to Certain Strictures upon the treatmont of a certain class of Destructive Patients," and he was again finally answered by Dr. Williams in the next number (January, 1868). This paper contained, also, extracts from various Continental and American Reviews, condemnatory of Dr. Sheppard's views.

I take the liberty of transmitting with this letter the numbers of the Journal of Mental Science containing these papers.

Dr. Sheppard's practice was also strongly censured by Professor Dr. Westphal in Germany, after his visit to England. It would, indeed, be difficult for me to convey to the Visitors of Colney Hatch, the extent of injury which the publication of Dr. Sheppard's paper inflicted on the progress of the non-restraint system on the continent, and I fear, from the tenour of your letter, that he still persists in his ill-advised course of treatment in these cases. I sincerely trust that the information which your circular will elicit, may induce the Visitors at Colney Hatch, entirely to discontinue the practice advocated by their Medical Superintendent.

II. With regard to the practice followed in this Asylum, in the treatment of a certain class of destructive patients, I would refer you to Dr. Williams's papers, already noticed, in which, I venture to think, the Visitors at Colney Hatch will find my plan of treatment clearly explained, with illustrative cases. Should any question arise thereon, I need scarcely say how gladly I shall furnish any further details.

As the Visitors at Colney Hatch appear desirous of learning the opinion of the Medical Profession on this question, I may perhaps be permitted to conclude this letter with a short paragraph which I translate from a paper I received in October last, from Professor Westphal, on the use of the hydrate of chloral. "The therapeutic value of this remedy (the hydrate of chloral), has been discovered exactly at the right moment, and enables us to give the last final blow to the practice of restraint in Germany. The adherents of that system have always brought forward cases of destructive mania, with attempts at injury, as those in which restraint is absolutely required. In these instances, the soothing sleep produced by this remedy will replace the restraint, and similar will be its results in the mania of General Paralysis attended with destructive violence."

I have the honour to be, Sir, Your most obedient servant,

C. LOCKHART ROBERTSON,

John S. Skaife, Esq., M.D., F.R.C.P., Medical Superintendent.

Clerk to the Visitors,

Colney Hatch Asylum.

Junius Brutus Booth v. John Wilkes Booth.

To the Editors of the Journal of Mental Science.

Gentlemeñ,

I notice a very strange mistake by Mons. Brierre de Boismont, which is translated and repeated on page 412 of the October number of your Journal. 